Universidade de São Paulo

Faculdade Medicina de Ribeirão Preto

\title{
Estudo de biocompatibilidade de matrizes de colágeno aniônico para reparo de defeitos ósseos
}

Lenaldo Branco Rocha
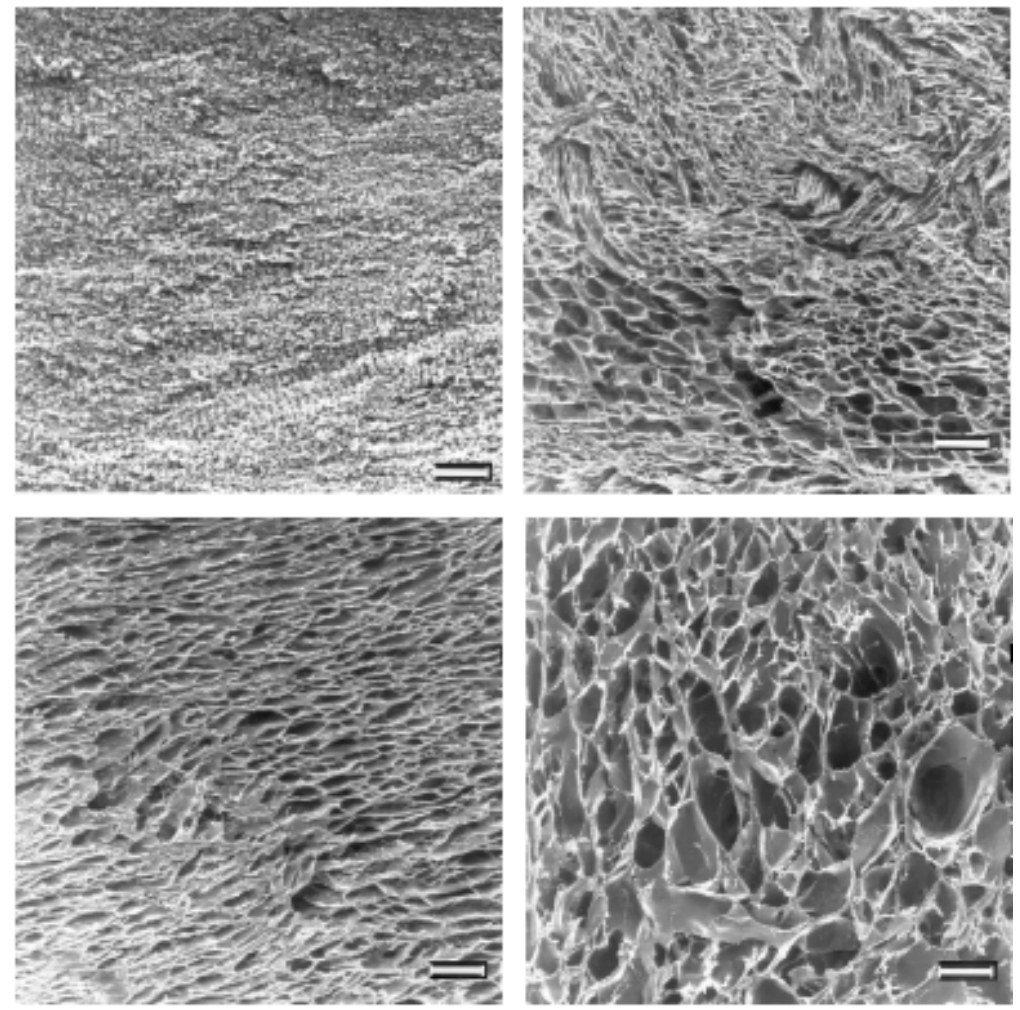

Ribeirão Preto

Estado de São Paulo - Brasil

Dezembro de 2000 


\section{Estudo de biocompatibilidade de matrizes de colágeno aniônico para reparo de defeitos ósseos}

\section{Lenaldo Branco Rocha}

Orientador: Prof. Dr. Marcos A. Rossi

Dissertação apresentada à Faculdade de Medicina de Ribeirão Preto, Universidade de São Paulo, como parte dos requisitos para obtenção do título de Mestre em Ciências - Área: Patologia Experimental

Ribeirão Preto

Estado de São Paulo - Brasil

Dezembro de 2000 
Trabalho realizado no Departamento de Patologia da Faculdade de Medicina de Ribeirão Preto - USP sob orientação do Prof. Dr. Marcos A. Rossi, com apoio financeiro da Fundação de Amparo à Pesquisa do Estado de São Paulo - FAPESP (Proc. 98/01294-6). 
Ao Prof. Dr. Marcos A. Rossi, por me ensinar o que é ser um cientista e me guiar nesse árduo caminho. 
Aos meus pais, Floriano e Eunice, pelo seu amor e apoio em todos os momemtos da minha vida. 
À Juliana, minha grande companheira nessa jornada e na minha vida, por estar sempre ao meu lado. 


\section{AGRADECIMENTOS}

Ao Prof. Dr. Marcos A. Rossi, pela orientação na execução desse trabalho.

Ao Prof. Dr. Gilberto Goissis, não só por ter fornecido as matrizes utilizadas, mas principalmente pelas críticas e conselhos a esse trabalho.

Às técnicas Maria Elena Riul, Monica Azevedo de Abreu e Ligia Baroza Santoro, pela imensa paciência e toda ajuda que me deram na realização desse estudo.

Ao técnico José Luíz de Souza, pela ajuda no processamento do material.

Ao Prof. Dr. Roberto Passeto Falcão e sua família, por me adotarem aqui em Ribeirão Preto.

Ao Sr. Júlio César Matos, por salvar a documentação desse trabalho.

À amiga Adriana Coelho de Souza, pela ajuda e amizade durante essa etapa.

À todos os funcionários e docentes do Departamento de Patologia da Faculdade de Medicina de Ribeirão Preto, por toda assistência que prestaram.

À FAPESP, pela bolsa de estudos concedida. 
Sumário

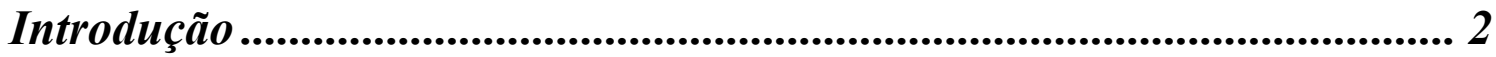

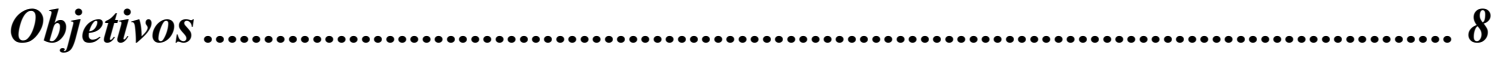

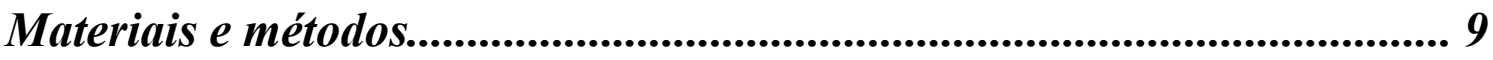

Caracterização morfológica das matrizes ............................................9

Biocompatibilidade das matrizes e resposta do tecido ósseo.................. 10

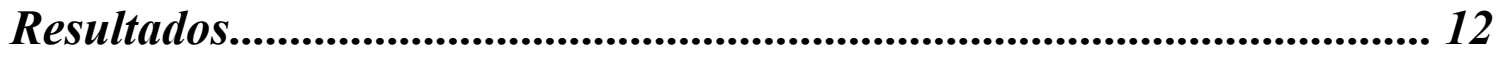

Caracterização morfológica das matrizes............................................. 12

Biocompatibilidade das matrizes e resposta do tecido ósseo................... 12

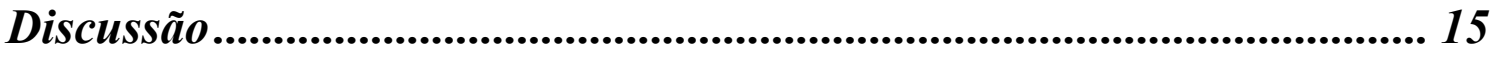

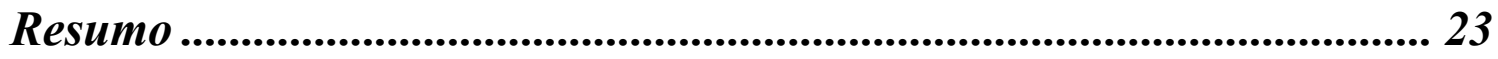

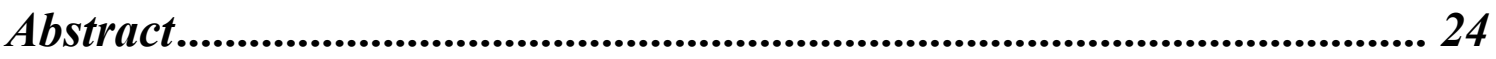

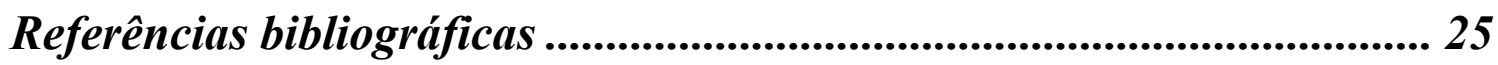

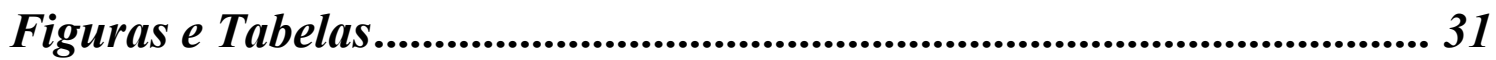




\section{INTRODUÇÃO}

Durante muito tempo a utilização de materiais na recuperação de órgãos ou tecidos ocorreu de maneira empírica. Pouca atenção era dada à investigação e compreensão das propriedades biológicas dos materiais empregados antes de se iniciar sua utilização clínica. Esperava-se apenas que o material fosse biologicamente inerte e que sua resistência mecânica fosse compatível com a da área de reparo. A busca do porquê e como esse material funcionava e era eficiente iniciava-se à medida que ele se mostrava útil. Não muito diferente de tantas outras ciências em que a necessidade de compreender um problema era suplantada pela urgência em resolvê-lo.

Com os enxertos para recuperação de defeitos ósseos a história não foi diferente. Relatos do uso de enxertos ósseos com sucesso datam do início do século XIX (Burwell, 1994). Contudo, esses enxertos limitavam-se ao osso autógeno e algumas tentativas de utilizar osso homógeno ou xenógeno. Todavia, mesmo com esse pequeno leque de materiais, havia grandes divergências quanto aos mecanismos envolvidos no reparo ósseo e ao papel dos enxertos. O papel do periósteo no processo de osteogênese foi alvo de discussão durante quase um século. Além disso, aspectos biológicos importantes do osso autógeno só foram descobertos na segunda metade do século XX, como por exemplo a proteína morfogenética do osso(Urist, 1965), responsável pela diferenciação de células mesenquimais em células da linhagem osteoblástica. Porém, mesmo desconhecendo os mecanismos de ação do osso autógeno, os resultados clínicos obtidos eram, e ainda são, considerados ótimos (Citardi \& Friedman, 1994). Apenas com o passar do tempo e os avanços do conhecimento na área da biologia óssea descobriu-se que esse enxerto possui propriedades biológicas próximas do 
ideal (DeLacure, 1994): não causa reações adversas locais ou sistêmicas (rejeição, inflamação, encapsulamento, etc.) e estruturalmente apresenta características de um compósito, ou seja, é constituído de diferentes materiais agindo em sinergismo para favorecer o reparo da estrutura óssea danificada. O defeito ósseo receptor recebe células osteogênicas viáveis e fatores de crescimento adequados à osteogênese, como a proteína morfogenética do osso (DeLacure, 1994). Também é propiciado suporte para migração de células osteogênicas provenientes de áreas adjacentes ao defeito (DeLacure, 1994). E ainda, com a migração de vasos sanguíneos e a formação de anastomoses com os vasos do enxerto, parte desse permanece viável e é incorporado ao osso neoformado (DeLacure, 1994; Prolo \& Rodrigo, 1985).

Entretanto, mesmo existindo um material com tais características biológicas, o tratamento de defeitos ósseos não permaneceu estático. Como na maioria dos tratamentos de qualquer enfermidade a solução de um problema costuma vir acompanhada de novos. Com o enxerto ósseo autógeno não foi diferente. Em primeiro lugar, esses enxertos necessitam de uma área doadora, aumentando a morbidade e o risco do tratamento (Van Heest \& Swiontkowski, 1999). E mais, nem sempre é possível obter um enxerto com volume suficiente para preencher o defeito ósseo existente, o que requer procedimentos adicionais de enxertia até a reabilitação almejada do paciente. Além dos problemas relacionados com os procedimentos cirúrgicos, o custo do tratamento e de recuperação do paciente é alto (Van Heest \& Swiontkowski, 1999). Ademais, fatores locais também podem limitar o uso dos enxertos autógenos, como área infectada, dificuldade de adaptação e fixação ao leito receptor e índices imprevisíveis de reabsorção do enxerto (Block \& Kent, 1997). 
Todos esses motivos estimulam a busca de alternativas para o tratamento dos defeitos ósseos. Grande impulso nessa busca ocorreu na duas últimas décadas, dado aos avanços das ciências de materiais e dos estudos da biologia do tecido ósseo, a busca por essas alternativas assumiu um aspecto mais "científico". Poucos dos avanços das últimas décadas basearam-se no procedimento de tentativa e erro. Sabe-se hoje que não existem materiais inertes, ocorrendo sempre algum tipo de interação entre o tecido receptor e o material implantado. Ora, tal conhecimento é crucial no controle da resposta biológica a um implante. É possível através de modificações da topografia da superfície do material implantado, tal como rugosidade e relevo, tentar direcionar a resposta biológica do tecido receptor (Boyan et al, 1996; Anselme, 2000; Healy et al ). Aspectos da estrutura química do material também podem ser alterados para se obter respostas biológicas previsíveis (Cook et al, 1997): adição de sítios de ligação (Cook et al, 1997, James et al, 1999; Rezania \& Healy, 1999), modificação da distribuição de cargas elétricas (Krukowski et al, 1995) ou combinação de diferentes moléculas em uma única estrutura (Pohunková et al, 1996; Park et al,2000), que podem favorecer a migração celular e/ou a adesão de fatores de crescimento.

No desenvolvimento de terapias para o reparo de defeitos ósseos os progressos no estudo da biologia do tecido ósseo não devem ser subestimados. A descoberta da proteína morfogenética do osso e o papel de outros fatores de crescimento (Transforming Growth Factos $\beta$, Insulin-like Growth Factor, Fibroblast Growth Factor, etc.) na osteogênese, a compreensão do papel do colágeno tipo I e outras moléculas da matriz extracelular no suporte e migração dos osteoblastos muito contribuíram para o desenvolvimento de uma 
série de materiais cuja resposta biológica é dirigida para favorecer o processo de osteogênese.

Utilizar esses conhecimentos é uma forma racional de desenvolver biomateriais específicos para o reparo de defeitos ósseos. Portanto, utilizar o colágeno tipo I como suporte para migração celular é, aparentemente, uma escolha razoável, visto que essa é a principal proteína estrutural dos mamíferos. No tecido ósseo corresponde a cerca de $90 \%$ da porção orgânica do tecido (Anselme, 2000). Além disso possui um papel direto no processo de mineralização óssea, visto que parte dos cristais de hidroxiapatita são depositados no interior da sua estrutura (Rho et al, 1998). Na migração dos osteoblastos o colágeno tipo I possui duas funções importantes. A primeira está ligada aos sítios de adesão RGD (-ArgGly-Asp-): os osteoblastos, através das integrinas, ligam-se diretamente ao colágeno tipo I via interação RGD-integrinas (Horton et al, 1996). A segunda refere-se ao suporte que esse tipo de colágeno oferece às outras proteínas do meio extracelular, como a osteopontina, envolvida no processo de adesão celular, a proteína Gla do osso (osteocalcina), que atua como nucleadora do processo de mineralização, e as proteoglicanas, moléculas que apresentam variadas funções no tecido ósseo, como "capturar" espaço para formação de tecido ósseo e modular a atividade de fatores de crescimento (Horton et al, 1996).

Ademais, outros aspectos são extremamente favoráveis ao uso dessa proteína no desenvolvimento de biomateriais. Inicialmente, por ser a principal proteína estrutural dos mamíferos, pode ser obtida em grande quantidade e a baixo custo, principalmente a de origem bovina. Apesar disso, ela pode ser utilizada com segurança entre animais de diferentes espécies sem causar respostas inflamatórias ou imunogênicas exacerbadas dada a pequena diferença estrutural que essa proteína possui entre os distintos mamíferos 
(DeLustro et $a L, 1987)$. E, além de poder ser usada isoladamente, é possível conjugá-la com outras moléculas, e obter um material que tenha respostas mais favoráveis do tecido ósseo em processo de reparo (Peiper et al, 1999; TenHuisen et al, 1995). O colágeno tipo I também permite algumas alterações na sua estrutura, como a remoção de grupos aminas (Radhika \& Sehgal, 1997; Radhika et al, 1999) e a hidrólise seletiva de grupos carboxiamidas dos resíduos de aspargina e glutamina em carboxílicos (Lacerda et al, 1998).

Após esse processo de hidrólise é obtida uma matriz de colágeno aniônico em pH fisiológico (Goissis et al, 1999) e com propriedade piro e piezelétrica superiores à do colágeno nativo (Plepis et al, 1996) e à do vinilideno fluoreto-trifluoretileno (Goissis et al, 1998). A quantidade de cargas negativas adicionadas ao colágeno pode ser variada de acordo com o tempo de hidrólise ao qual o colágeno é submetido (ver tabela 2) sem grandes prejuízos à estabilidade térmica do colágeno (Goissis et al, 1999) e sem a perda da estrutura química secundária do colágeno (Goissis et al, 1998). Tais matrizes já se mostraram eficazes quando usadas na forma de membrana para o tratamento de lesões periodontais (Cirelli et al, 1997)

O efeito de cargas elétricas sobre células não é uma questão recente. Na década de 60 foi demonstrado que a adesão de células in vitro depende da presença de cargas elétricas negativas na superfície do substrato de cultura (Rappaport et al, 1960). Nessa mesma década foi levantada a questão do papel de fenômenos bioelétricos na osteogênese (Urist, 1965). O tecido ósseo quando submetido a ação de correntes elétricas sofre aposição na região do cátodo e reabsorção na região do ânodo (Spadaro, 1997). Matrizes ósseas desmineralizadas com ação osteoindutora possuem uma quantidade relativamente elevada de cargas elétricas negativas na sua superfície, e quando privadas dessas cargas, perdem a 
capacidade osteoindutora (Eriksson, 1976). Contudo, avanços significativos no uso de materiais com superfície carregada eletricamente no processo de reparo ósseo ainda não foram feitos.

Nesse estudo o processo de hidrólise de grupos carboxiamidas citado foi aplicado ao pericárdio bovino com o objetivo de se produzir uma matriz de suporte para reparo do tecido ósseo. Esse material tem como vantagens imediatas a facilidade de obtenção, o baixo custo de produção. Cabe agora avaliar se essas matrizes possuem biocompatibilidade adequada com áreas de reparo ósseo e averiguar se são capazes de permitir a recuperação adequada de defeitos ósseos nas condições aqui impostas. 


\section{OBjetivos}

O presente estudo objetivou:

1- Identificar, através de microscopia óptica e eletrônica de varredura, as alterações estruturais causadas no pericárdio bovino pelo processo de hidrólise seletiva dos grupos carboxiamidas em carboxilícos, realizado por 24 (BP24), 36 (BP36) e 48 (BP48) horas;

2- Avaliar a biocompatibilidade e a resposta local às três matrizes obtidas após implante em defeitos ósseos criados em tíbias de rato, comparando com defeitos do mesmo tipo sem a presença de material algum. 


\section{MATERIAIS E MÉTODOS}

\section{Caracterização morfológica das matrizes}

As matrizes de colágeno aniônico escolhidas para esse estudo foram as que passaram pelo processo de hidrólise por 24 (BP24), 36 (BP36) e 48 (BP48) horas. Todas as matrizes foram fornecidas pelo Prof. Dr. Gilberto Goissis do Instituto de Química de São Carlos USP.

Amostras de $1 \mathrm{~cm}^{2}$ de cada matriz de colágeno aniônico foram coletadas para análise através de microscopia óptica e microscopia eletrônica de varredura. Pericárdio bovino foi analisado concomitantemente para servir de referência na identificação das modificações.

As amostras das matrizes para microscopia óptica foram incluídas em parafina; passos anteriores a esse, como desidratação e diafanização, não foram executados, visto que as matrizes foram providas liofilizadas. O pericárdio bovino seguiu o processamento rotineiro para inclusão em parafina. Foram realizados cortes seriados de $5 \mu \mathrm{m}$, os quais foram corados pelo método pentacrômico de Movat. A avaliação dos cortes foi efetuada em um microscópio Zeiss Jenaval (Carl Zeiss, Alemanha). Imagens das matrizes foram digitalizadas para morfometria de poros encontrados com o programa NIH Image 1.62 (National Institutes of Health, EUA). Foram medidos 50 poros de cada matriz. A avaliação da distribuição dos poros entre as matrizes foi efetuada utilizando a análise de freqüência de distribuição. Os resultados obtidos foram avaliados com o teste de análise de variância (one-way ANOVA) seguido do teste de múltipla comparação de Bonferroni. A análise de variância, o teste de Bonferroni e a freqüência de distribuição foram realizadas utilizando o programa Prism 3 (GraphPad Inc., Califórnia, EUA). 
As demais amostras foram cortadas transversalmente e coladas em suportes de alumínio com cola de prata e recobertas com ouro em um aparelho Emitech K650 (Emitech, Alemanha). Por se tratar de material liofilizado, desidratação e secagem em ponto crítico das matrizes de colágeno aniônico não foi efetuada. A amostra de pericárdio bovino foi desidratada em soluções de concentrações crescentes de etanol e secada em ponto crítico em um aparelho Bal-Tec CPD030 (Bal-Tec, Liechtenstein). As preparações foram analisadas em um microscópio eletrônico de varredura Zeiss DSM 940A (Carl Zeiss, Alemanha) operado a $10 \mathrm{kV}$.

\section{Biocompatibilidade das matrizes e resposta do tecido ósseo}

O estudo da biocompatibilidade e da resposta do tecido ósseo foi realizada em defeitos criados cirurgicamente em tíbias de ratos. Foram utilizados nesse experimento quarenta ratos da linhagem Wistar pesando entre 220 e 250 gramas fornecidos pelo Biotério Central do campus da USP de Ribeirão Preto.

Para o procedimento cirúrgico os animais foram anestesiados com éter etílico e mantidos sob inconsciência controlada durante todo o procedimento. Após a tricotomia da face medial de ambas pernas, a desinfecção local foi feita com álcool iodado. Procedeu-se a incisão na região da sinostose fíbulo-tibial, com único golpe envolvendo pele, músculo e periósteo. Feita sindesmotomia e afastamento adequado dos tecidos moles, uma fenestração monocortical foi realizada em cada tíbia do animal com fresa odontológica $\mathrm{n}^{\mathrm{o}} 701$, montada em peça-reta, à aproximadamente 1000 RPM e sob irrigação abundante com solução salina $0,9 \%$ estéril. Os defeitos gerados mediam aproximadamente $2 \times 1 \mathrm{~mm}$. Antes da 
implantação, as matrizes foram hidratadas com solução salina $0,9 \%$ estéril. Após a colocação das matrizes ou execução do defeito vazio, o periósteo, o músculo e a pele do animal foram reaproximados e suturadas com fio de seda 3-0. Durante o período pósoperatório os ratos foram mantidos em gaiolas individuais com ração apropriada e água $\mathrm{ad}$ libitum.

Cada defeito foi preenchido com uma das matrizes citadas BP24, BP36 e BP48. Um quarto defeito foi mantido sem nenhuma matriz. Os ratos foram divididos em 2 grupos experimentais de 5 animais. E nos distintos grupos experimentais cada animal recebeu a matriz BP24 e BP48 ou a BP36 e nenhum implante (defeito vazio). Dez animais, 5 de cada grupo experimental, foram sacrificados $3,7,15$ e 30 dias após a cirurgia. As pernas foram dissecadas e as tíbias removidas e imersas imediatamente em solução de formol a 10\% em tampão fosfato e fixadas por 24 horas. Após a fixação, os tecidos foram descalcificados com solução de ácido tricloroacético a $10 \%$ por 3 dias. A seguir o ácido foi neutralizado com solução de sulfato de sódio a 5\% por 12 horas. Após a desidratação e a diafanização, a inclusão em parafina foi realizada de maneira que pudessem ser obtidos cortes longitudinais seriados dos defeitos criados. As secções foram coradas com hematoxilina e eosina e examinadas em microscópio óptico. 


\section{RESULTADOS}

\section{Caracterização morfológica das matrizes}

Duas diferenças foram evidentes ao analisar as matrizes de colágeno aniônico com o pericárdio bovino. O primeiro aspecto morfológico observado foi a completa remoção de todas as células do interior das matrizes com 24 ou mais horas de hidrólise (Figura 1). E conjuntamente, foi notada a completa remodelação do arranjo das fibras de colágeno (Figuras 1 e 2). $\mathrm{O}$ aspecto compacto e a orientação das fibras nativas, entrecruzadas e paralelas à superfície do pericárdio, transformou-se em uma estrutura com aspecto semelhante ao de uma esponja. O aspecto fibrilar do colágeno tornou-se uma estrutura composta de fitas (Figura 2). Os poros abertos mostravam-se irregularmente distribuídos, com diâmetros heterogêneos (Tabela 1 e Figura 3) e interconectados em todas as matrizes. A medida do diâmetro dos poros das matrizes BP24 e BP48 foi significativamente maior que a da matriz BP36 (Figura 3).

\section{Biocompatibilidade das matrizes e resposta do tecido ósseo}

De maneira geral todas as matrizes permitiram a proliferação de tecido ósseo no seu interior. Nesse processo não foi observado nenhuma reação adversa como resposta inflamatória acentuada ou encapsulamento das matrizes.

Três dias após a cirurgia (Figura 4) o defeito vazio encontrava-se preenchido por coágulo associado a poucos neutrófilos e macrófagos, sem a presença de células gigantes multinucleadas. Nos defeitos que receberam as matrizes, hemácias podiam ser vistas preenchendo os poros delas. Não havia sinais de reabsorção das matrizes, assim como 
modificação da estrutura de esponja. A reação inflamatória presente era semelhante a da trepanação vazia.

No sétimo dia (Figura 5, detalhe na figura 8) todas as matrizes estavam preenchidas por uma população variada de células, composta principalmente de hemácias, células inflamatórias e células mesenquimais não identificadas. A maioria das células parecia estar em contato com as fibras do implante. Na periferia dos implantes havia áreas de neoformação óssea originárias do endósteo e em íntimo contato com as fibras de colágeno aniônico. A ausência de reabsorção ou tentativa de reabsorção das matrizes mantinha-se. Os defeitos vazios estavam preenchidos por osso imaturo. Não foi observado qualquer aumento do processo inflamatório ou qualquer reação adversa às matrizes.

No décimo quinto dia após a cirurgia (Figura 6) as matrizes perderam o aspecto esponjiforme. Áreas de formação de tecido ósseo, originárias tanto do periósteo quanto do endósteo, ocupavam áreas antes ocupadas pelas matrizes. Aparentemente o processo de reparo do tecido estava sendo orientado pelo direcionamento das fibras de colágeno aniônico. No grupo implantado com BP24 e BP48, medula óssea estava presente junto a algumas regiões de neoformação óssea. Enquanto isso o tecido ósseo em formação na cavidade vazia mostrava-se em fase de remodelação, sendo que na superfície a diferenciação em osso cortical era aparente.

Por fim, no trigésimo dia, o defeito vazio estava recuperado com osso cortical neoformado, apesar de um pouco mais fino que a estrutura original. As trepanações preenchidas com as matrizes de colágeno aniônico também estavam preenchidas com tecido ósseo, embora, no lugar de osso cortical tenha sido observado osso trabecular nos defeitos preenchidos com BP24 e BP48. No defeito preenchido com BP36 estavam 
presente pequenas áreas de medula óssea no interior da estrutura óssea, além dessa possuir o aspecto de uma matriz fibrosa em processo de calcificação e não o de uma estrutura óssea compacta. Em nenhum grupo ou momento foi notada a proliferação de tecido conjuntivo no interior das matrizes ou a formação de cartilagem. 


\section{DisCUSSÃO}

Os resultados do presente estudo demonstram claramente que o processo de hidrólise seletiva de grupos carboxamidas em carboxílicos causa modificações na estrutura nativa do pericárdio bovino, removendo células e transformando a estrutura compacta e fibrilar do colágeno nativo em uma estrutura semelhante a uma esponja. Além disso foi observado que as matrizes obtidas permitiram o reparo de trepanações ósseas sem induzir reação adversa.

Fato importante na resposta biológica às matrizes é que não foi encontrada evidência de reabsorção das matrizes para permitir a neoformação óssea. $\mathrm{O}$ aspecto apresentado sugere que as matrizes foram incorporadas aos tecidos dos animais, e uma eventual reabsorção ocorreu junto com a remodelação que um tecido em reparo sofre, especialmente o tecido ósseo. Isso é incomum em biomateriais, desde que são facilmente distinguíveis do tecido em que são implantados, havendo, inclusive, uma interface clara entre ambos. Tal resposta foi completamente inesperada, visto que, com exceção do osso autógeno, nenhum outro biomaterial é incorporado à estrutura do tecido ósseo sem deixar vestígios da sua presença. A resposta usual da área de reparo é reabsorver o material implantado para criar espaço para osteogênese. Porém, em período experimental algum foi observado reabsorção das matrizes de colágeno aniônico para permitir a migração do tecido ósseo. Todo o processo de osteogênese ocorreu com a presença das matrizes de colágeno aniônico, no $7^{\circ}$ dia na periferia, sendo possível distinguir o arcabouço das matrizes em regiões mais profundas e, a partir do $15^{\circ}$ dia pós-implante, tornou-se praticamente impossível diferenciar a estrutura das matrizes dos tecidos dos animais.. 
Apesar de não ter sido realizada uma avaliação quantitativa da resposta inflamatória causada pelo colágeno aniônico, qualitativamente pareceu não haver diferença em relação ao grupo controle, cuja reação inflamatória foi causada pelo truma cirúrgico. Essa é mais uma resposta incomum a um biomaterial. Com 3 dias pós-operatório deveria haver uma quantidade de neutrófilos muito superior ao grupo controle, e a partir do $7^{\circ}$ dia uma resposta inflamatória crônica com áreas de reabsorção do material. Mesmo se tratando de colágeno no aspecto básico do material deveria ter ocorrido uma reação mais intensa. Nada disso foi observado, de alguma maneira o processo de hidrólise de grupos carboxiamidas criou uma estrutura que o organismo do animais reconheceram como perfeitamente aceitável. Esses dois aspectos da resposta do área reparo mostram que as matrizes de colágeno aniônico são altamente biocompatíveis.

Outros materiais com cargas elétricas para o tratamento de defeitos ósseos já foram testados anteriormente, como o DEAE-Sephadex (Krukowski et al, 1990) e o Dextran (Snyders et al, 1993). Todavia, esses materiais não foram desenvolvidos para servir de suporte para a osteogênese, e sim para uso em cromatografia. Mesmo com os resultados desses estudos sendo por vezes animadores, uma análise crítica mostrou que eles apenas funcionaram como sinalizadores para o que deve ser procurado e desenvolvido no campo de biomateriais com cargas elétricas. A possível utilização clínica desses materiais estaria limitada pela composição das resinas, especialmente por não serem biodegradáveis (Krukowski et al, 1990; Snyders et al, 1993). Em alguns casos houve relato de formação de reação inflamatória intensa, inclusive com a presença de células gigantes multinucleadas (Krukowski et al, 1990). Associar esse resultados com os obtidos com o colágeno aniônico demonstram que não é a simples apenas a presença de cargas elétricas que tornou o 
colágeno uma molécula mais bio compatível. Uma série de interações que invariavelmente ocorrem entre o biomaterial e o tecido do ser vivo devem ocorrido fazendo com que, nas condições experimentais utilizadas, o reparo ocorresse sem reações, que apesar de benéficas em algumas situações (remover um material que pudesse atrapalhar a função da estrutura óssea, por exemplo), levam a atrasos na neoformação óssea. Não é só a presença de grupos carboxílicos, e sim toda estrutura do colágeno aniônico envolvida no processo de osteogênese, já que algumas esferas de Sephadex possuem grupos carboxílicos e ainda sim causaram reações inflamatórias intensas.

As modicações estruturais das matrizes em relação ao pericárdio bovino também foram importantes para favorever a osteogênese. Primeiramente, deve ser lembrado que a fonte da qual o colágeno foi obtido, o pericárdio bovino, possui outros componentes estruturais além do colágeno tipo I e estes poderiam prejudicar o comportamento biológico das matrizes derivadas do pericárdio. Entre esses os que requerem maior atenção são as células presentes no tecido nativo. A partir delas uma série de reações indesejáveis pode ocorrer, como calcificações distróficas decorrentes dos fosfolipídios da membrana celular (Rossi et al, 1986; Rossi et al, 1990) e reações imunogênicas contra antígenos de superfície (Pachence, 1996). Tais reações podem causar danos ainda maiores à área que deveria ser reparada, visto que células fagocitárias podem aumentar o defeito do leito receptor. Portanto, para que o material possa ser implantado com maior segurança é imperativo que a matriz obtida com o processo de hidrólise em questão não possua nenhuma célula na sua estrutura. De fato, ao comparar o pericárdio bovino nativo com as matrizes na microscopia óptica uma das características facilmente notada é a ausência de células em toda estrutura das matrizes. 
Dessa forma um elemento que poderia obscurecer a resposta positiva ao colágeno aniônico, e consequentemente a sua biocompatibilidade, foi eleminado.

Outro aspecto estrutural que sofreu profundas modificações foi a organização das fibras de colágeno. Como já era conhecido (Lacerda et al, 1998) a adição de cargas elétricas negativas à estrutura dessa proteína modifica o seu arranjo fibrilar, causando modificações em toda organização do pericárdio bovino nas condições analisadas. A estrutura fibrilar densa observada no colágeno nativo passou a ter um aspecto de fita com a formação de poros com os mais variados diâmetros espalhados no arcabouço das matrizes, associado ao rearranjo tridimensional do empacotamento do colágeno nas matrizes em relação ao colágeno nativo. Tal característica é favorável à utilização das matrizes em uma área de reparo tecidual, já que permite a neoformação tecidual no seu interior à medida que o material e removido enquanto que materiais compactos precisam ser reabsorvidos para permitir a proliferação celular no seu interior. Com a presença de poros e espaço para a migração celular a quantidade de material a ser reabsorvido será menor e a gênese tecidual será mais rápida. Somando-se a isso o fato que durante a regeneração óssea as matrizes de colágeno aniônico são incorparatas ao tecido, tem-se uma situção muito favorável para a osteogênese.

Em alguns materiais o diâmetro dos poros também influencia o processo de migração tecidual, o que é claramente notado com blocos de hidroxiapatita, cujos poros devem medir entre 100 e $500 \mu \mathrm{m}$ para que permitam uma migração celular adequada e principalmente a invasão de capilares(Chand et al, 2000), cruciais para que ocorra a osteogênese e não a condrogênse. Há que se considerar também que o tamanho e a densidade de poros é 
diretamente proporcional ao número de intercomunicações entre eles, e com isso a migração celular através do arcabouço do material é facilitado em estruturas mais porosas. Contudo não deve ser feita uma avaliação do papel dos poros nas matrizes de colágeno aniônico baseando-se nos resultados de outros materiais. Uma associação entre aspecto estrutural e resposta in vivo é o que de fato irá mostrar se os poros dessas matrizes foram efetivos em permitir a proliferação celular. Portanto, retomando os resultados das características histológicas das áreas de reparo com as matrizes de colágeno aniônico, notase que células de variados tamanhos atingiram regiões profundas das matrizes em no máximo 7 dias, mesmo com as matrizes tendo poros com diâmetros tão heterogêneos. E ainda, como o resultado final, ou seja, com 30 dias, o tecido encontrado foi osso trabecular, não há dúvidas que houve espaço para proliferação vascular.

Contudo, além da presença dos poros e seu papel positivo no quadro histológico encontrado, a reorganização das fibras de colágeno pode ter influenciado a migração de osteoblastos. Como os osteoblastos aderem diretamente ao colágeno tipo I principalmente via interação integrinas-sequências RGD, é possível que a nova estrutura apresentada pelo colágeno tenha algum efeito na distribuição desses grupos. E mais, o porcesso de hidrólise causa um aumento no número de grupos RGD no colágeno, adicionando mais 2 grupos por molécula (Goissis, comunicação pessoal). Como conseqüência, é possível que essas modificações possam ter causado alteração no padrão de adesão e migração de osteoblastos. Logicamente os resultados agora obtidos não fornecem elementos concretos para se comprovar essa hipótese, mas sob a luz de estudos demonstrando a inter-relação entre os osteoblastos e o colágeno, e de trabalhos em que seqüências RGD são adicionados 
à biomateriais, pode-se suspeitar que esse seja um dos mecanismos envolvidos na resposta biológica às matrizes de colágeno aniônico.

Apesar da adição de cargas elétricas negativas ao colágeno ter causado modificações desejáveis na estrutura da matriz nativa, é provável que seus efeitos no reparo da trepanação não tenha ficado limitado à isso. Quando um material é implantado num organismo vivo a primeira interação que ocorre é a adsorsão de componentes dos fluidos corporais na estrutura do implante (Shelton et al, 1988). Esse fenômeno é tão importante quanto a própria estrutura química do material, pois será essa camada adsorvida é que muitas vezes irá interagir com células. Mesmo que, de uma maneira geral, não se conheça os detalhes dessa interação, conhecendo as características químicas de algumas moléculas do meio extracelular é possível imaginar o que possa ocorrer com a presença do colágeno aniônico. As células de um ser vivo interagem com um ambiente complexo com moléculas possuindo as mais variadas características químicas. Entre essas encontram-se as proteoglicanas que têm como uma característica estrutural a presença de cargas elétricas negativas, devido à presença de grupos sulfatos e carboxílicos (Wight et al, 1992; Jackson et al, 1991). É através desses grupos que a função de fatores de crescimento são moduladas e dessa forma que eles são apresentados para as células (Bokoch, 1995; Luster,1998). É provável que com a presença do colágeno aniônico mais grupos carboxílicos estejam disponíveis e, consequentemente, mais sítios de ligação para fatores de crescimento. E como se tratava de uma área de reparo ósseo, os fatores de crescimento liberados estavam comprometidos com o reparo desse tecido, justificando, talvez, a velocidade do reparo ósseo e, possivelmente, a formação de osso trabecular e a presença de medula óssea. Mais uma vez as informações fornecidas pelos resultados conseguidos apenas permitem uma 
conjectura de quais seriam as interações entre os tecidos e as matrizes de colágeno aniônico.

Por outro lado as proteoglicanas também podem ser encontradas recobrindo toda superfície de uma célula. Ém um sistema isolado isso poderia significar em falha na adesão celular por repulsão de cargas. Mas, devido ao conjunto de interações que ocorrem in vivo, e mais, dada à presença de sítios com cargas positivas na membrana plasmática o quadro encontrado pode ser bem diferente. Em estudo realizado com resinas possuindo diferentes cargas elétricas como substrato para osteoblastos em cultura (Davies, 1986), foi notado que sobre a resina com carga positiva as células assumiam uma forma achatada, parecendo estar em repouso, e em contato íntimo com a estrutura de suporte, por toda extensão da membrana plasmática. Por outro lado, as células cultivadas sobre cargas negativas estavam em contado com o substrato em alguns pontos, entretanto essas células tinham um aspecto ativo, com diversos prolongamentos na membrana celular. Tudo isso pode estar relacionado com o fato dos sítios de ligação na membrana ter influência direta no metabolismo celular. Proteínas do citoplasma, como a vinculina e a talina, estão ligadas às moléculas de adesão, no lado da membrana celular, e aos filamentos de actina no interior do citoplasma, de maneira que modificações na conformação do sítio de adesão causa alterações em todo conjunto, podendo, como resultado final, ativar ou inibir moléculas de sinalização intracelular (Anselme, 2000; Gronowicz \& McCarthy, 1996). Em resumo, a atividade metabólica celular depende, entre outros fatores, diretamente de como e em que a célula está aderida. O que está envolvido na interação entre as matrizes de colágeno aniônico e o tecido ósseo é até o momento desconhecido, porém a alta biocompatilidade do material de corrente dessas interações não pode ser negado. 
Certamente a dúvida inicial a respeito das matrizes de colágeno aniônico para uso no reparo de defeitos ósseos, a sua biocompatibilidade, foi devidamente esclarecida. Porém, apartir desse momento deve ser avaliado qual o horizonte dessas matrizes na terapêutica dos defeitos defeitos. Já que biocompatibilidade não será um aspecto preocupante, outros aspectos tão importantes quanto esse devem ser avaliados, a começar pelas propriedades osteocondutoras do material, visto que o modelo experimental utilizado nesse estudo, oferece limitações nessa análise. Mesmo assim pode-se afirmar com segurança que as matrizes de colágeno aniônico um dia serão uma alternativa eficiente à mão dos cirurgiões das diversas áreas das ciências biomédicas em que haja demanda por esse tipo de material. Com vantagens também no aspecto econômico, pois a matéria prima básica o colágeno tipo I pode ser obtido facilmente (pericárdio bovino, tendão) e baixo custo, associado ao também baixo custo de produção das matrizes.

Em conclusão, o que se pode aprender com este estudo é que (a) o processo de hidrólise seletiva de grupos carboxiamidas em carboxílicos aplicado ao pericárdio bovino produz matrizes acelulares com poros interligados de diversos diâmetros ao longo de toda sua estrutura e (b) a implantação dessas matrizes em trepanações ósseas não causa nenhuma reação adversa, sendo incorporado àrea de reparo, permitindo o reparo da estrutura óssea alterada com a formação de osso trabecular. 


\section{RESUMO}

Objetivo Avaliar as modificações estruturais do pericárdio bovino após hidrólise seletiva de grupos carboxiamidas em carboxílicos e resposta biológica em defeitos ósseos reparados com as matrizes de colágeno aniônico.

Material e métodos Amostras das matrizes modificadas foram comparadas com amostras de pericárdio bovino nativo através de microscopia óptica e de microscopia eletrônica de varredura. A resposta biológica foi avaliada implantando fragmentos das matrizes em trepanações criadas em tíbias de ratos. O reparo dos defeitos foi estudado 3, 7 , 15 e 30 dias pós-implantação usando-se microscopia óptica.

Resultados O processo de hidrólise seletiva de grupos carboxamidas em carboxílicos removeu completamente as células intersticiais do pericárdio bovino e transformou a estrutura compacta e fibrilar do colágeno nativo em uma estrutura esponjiforme. Além disso, foi observado que as matrizes modificadas permitiram o reparo das trepanações ósseas com a formação de osso trabecular, sem induzir nenhuma reação adversa.

Conclus̃̃es A hidrólise utilizada aplicada ao pericárdio bovino produz uma matriz acelular com poros distribuídos na sua estrutura. Essas matrizes são biocompatíveis, não induzem reação inflamatória e permitem o reparo de trepanações ósseas experimental mente induzidas. 


\section{Abstract}

Objective Evaluate the structural modifications in the bovine pericardium after selective hydrolysis of carboxiamides groups into carboxilic and the biological response in bone defects repaired using the anionic collagen matrices.

Material and methods Samples of the modified matrices were compared to samples of native bovine pericardium using light microscopy and scanning electron microscopy. The biological response were evaluated implanting fragments of the matrices into defects made in rat tibias. The repair of the defects were evaluated $3,7,15$, and 30 days after implantation using light microscopy.

Results The process of selective hydrolysis of carboxiamides groups into carboxilic completely removed the interstitial cells of the bovine pericardium and turned the compact and fibrilar structure of native collagen into a sponge-like structure. Besides, it was observed that the modified matrices allowed the repair of the bone defects through the formation of cancellous bones, without any side reaction.

Conclusions The used hydrolysis applied to bovine pericardium produces a acellular matrix with pores distributed along its structure. These matrices are biocompatible, they do not induce any inflammatory reaction and allow the repair of experimentally induced bone defects. 


\section{REFERÊNCIAS BIBLIOGRÁFICAS}

Anselme K. Osteoblast adhesion on biomaterials. Biomaterials, v.21: p.667-681, 2000.

Block MS, Kent JN. Sinus augmentation for dental implants: the use of autogenous bone. J Oral Maxillofac Surg, v.55, p.1281-1286, 1997.

Bokoch, G.M. Chemoattractant signalling and leukocyte activation. Blood, v.86, p.1649-1660, 1995.

Boyan BD, Hummert TW, Dean DD, Schwartz Z. Role of material surfaces in regulating bone and cartilage cell response. Biomaterials, v.17: p.137-146, 1996.

Burwell RG. History of bone grafting and bone substitutes with special reference to osteogenic induction. In: Urist MR, O'Connor BT, Burwell RG. Bone Grafts, Derivatives \& Substitutes. Butterworth Heinemann Ltd. p 3-102, 1994.

Chang BS, Lee CK, Hon KS, Youn HJ, Ryu HS, Chung SS, Park KW. Osteoconduction at porous hydroxyapatite with various pore configurations. Biomaterials, v.21, p.1291$1298,2000$.

Cirelli, J.A.; Marcantonio Jr, E.; Marcantonio, R.A.C.; Lia, R.C.C.; Goissis, G.; Rossa Jr, C. Evaluation of anionic collagen membranes in the treatment of class II furcation lesions: an histometric analysis in dogs. Biomaterials, v.18, p.1227-1234, 1997.

Citardi MJ, Friedman CD. Nonvascularized autogenous bone grafts for craniofacial skeletal augmentation and replacement. Otolaryngol Clin North Am, v.27, p891-910, 1994;. 
Cook AD, Hrkach JS, Gao NN, Johnson IM, Pajvani UB, Cannizaro SM, Langer R. Characterization and development of RGD-peptide-modified poly(lactic acid-colysine) as an interactive resorbable biomaterial. J Biomed Mater Res, v.35, p.513-523, 1997.

DeLacure MD. Physiology of bone healing and bone grafts. Otolaryngol Clin North Am, v.27, p.859-874, 1994.

DeLustro F, Smith ST, Sundsmo J, Salem G, Kincaid S, Ellingsworth L. Reaction to injectable collagen: Results in animal model and clinical use. Plast Reconstr Surg, v.79, p.581-592, 1987.

Erikson, C Bone morphogenesis and surface charge. Clin Orthop, v.121, p.295-302, 1976.

Goissis, G.; Piccirili L.; Goes, J.C.; de Guzzi Plepis, A.M.; Das-Gupta, D.K. Anionic collagen: polymer composites with improved dielectric and rheological properties. Artif Organs, v.22, p.203-209, 1998.

Goissis, G; Rossi, MA; Bet, MR; Rocha, LB Anionic collagen-elastin matrices as scaffold for bone tissue growth: preparation, characterization and implant response. Artif Organs, v.23, p.640, 1999.

Gronowicz, G.; McCarthy, M.B. Response of human osteoblast to implant materials: integrin- mediated adhesion. J Bone Joint Surg, v.14, p. 878-887, 1996.

Healy KE, Thomas CH, Rezania A, Kim JE, Mckeown PJ, Lom B, Hockberger PE. Kinetics of bone cell organization and mineralization on materials with patterned surface chemistry. Biomaterials, v.17, p.195-208, 1996. 
Horton MA, Townsend P, Nesbitt. Cell surface attachment molecules in bone. In: Bilezikian JP, Raizy LG, Rodan GA, editors. Principles of bone biology. Academic Press p 217-230, 1996.

Jackson RL, Busch SJ, Cardin AD. Glycosaminoglycans: molecular properties, protein interactions, and role in physiological processes. Physiol Rev, v.71, p.481-539, 1991.

James K, Levene H, Parsons R, Kohn J. Small changes in polymer chemistry have a large effect on the bone-implant interface: evaluation of a series of degradable tyrosiderived polycarbonates in bone defects. Biomaterials, v.20: p.2203-2212, 1999.

Krukowski M, Eppley B, Mustoe T, Osdoby P. Hard and soft connective tissue growth and repair in response to charged surfaces. In Davies JE, Shelton RM. The bonebiomaterial interface. University of Toronto Press, p 275-284, 1995.

Krukowski M, Shively RA, Osbody P, Eppley BL. Stimulation of craniofacial and intramedulary bone formation by negatively charged beads. J Oral Maxillofac Surg, v.48, p.468-475, 1990.

Lacerda C, Plepis AMG, Goissis G. Selective hydrolysis of carboxyamides of aspargine and glutamine residues of collagen: Preparation and characterization of anionic collagen matrices for biomaterial applications. Quim Nova, v.21: p.267-271, 1998.

Luster, A.D. Chemokines - Chemotatic cytokines that mediate inflammation. New England Med J, v.338, p.436-445, 1998.

Pachence JM. Collagen-based devices for soft tissue repair. J biomed Mater Res, v.33, p.35-40, 1996.

Park YJ, Lee YM, Park SN, Sheen SY, Chung CP, Lee SJ. Platelet derived growth factor 
releasing chitosan sponge for periodontal bone regeneration. Biomaterials, v.21, p.153$59,2000$.

Pieper JS, Ooerhof PJ, Dijkstra PJ, Veerkamp JH, van Kuppevelt TH. Preparation and characterization of porous crosslinked collagenous matrices containing bioavailable chondroitin sulphate. Biomaterials, v.20, p.847-858, 1999.

Plepis, A.M..C.; Goissi, G.; Das-Gupta, D.K. Dielectric and pyroelectric characterizationof anionic and native collagen. Pol Eng Sci, v.36, p.2932-2938, 1996.

Pohunková H, Stehlík J, Váchal J, Cech O Adam M. Morphological features of bone healing under effect of collagen-graft-glycosaminoglycan copolymer supplemented with the tripeptide Gy-His-Lys. Biomaterials; v.17, p.1567-1574 1996.

Prolo DJ, Rodrigo JJ. Conteporary bone graft physiology and surgery. Clin Orthop, v.200, p.322- 342, 1985.

Radhika M, Babu M, Sehgal PK. Cellular proliferation on desaminated collagen matrices. Comp Biochem Physiol C Pharmacol Toxicol Endocrinol, v.124, p.131-139, 1999.

Radhika M, Sehgal PK. Studies on the desamidation of bovine collagen. J Biomed Mat Res, v.35. p.497-503, 1997.

Rappaport C, Poole JP, Rappaport HP. Studies on properties of surfaces required for growth of mammalian cells in synthetic medium. Exp Cell Res, v.20, p.465-510, 1960.

Rezania A, Healy KE. Biomimetic peptide surfaces that regulate adhesion, spreading, cytoskeletal organization and mineralization of the matrix deposited by osteoblast-like cells. Biotech Prog, v.15 p.19-32, 1999. 
Rho JY, Kuhn-Spearing L, Zioupos P. Mechanical properties and the hierarchical structure of bone. Med Eng Phys, v.20, p.92-102, 1998.

Rossi MA, Braile DM, Teixeira MDR, Carillo SV. Calcific degeneration of pericardial valvular xenografts implanted subcutaneously in rats. Int $\mathrm{J}$ Cardiol, v.12, p.331-339, 1986.

Rossi MA, Domingo DM, Teixeira MDR, Souza DRS, Peres LC. Lipid extraction attenuates the calcific degeneration of bovine pericardium used in cardic valve bioprostheses. J Exp Path, v.71, p.187-196, 1990.

Shelton RM, Rasmussen AC, Davies JE. Protein adsorption at the interface between charged polymer substrata and migrating osteoblasts. Biomaterials, v.9, p.24-29, 1988.

Snyders RV, Eppley BL, Krukowski M, Delfino JJ. Enhancement of repair in experimental calvarial bone defects using calcium sulfate and dextran beads. J Oral Maxillofac Surg, v.51, p.517-524, 1993.

Spadaro, JA Mechanical and electrical interactions in bone remodeling. Bioelectromagnetics, v.18, p. 193-202, 1997.

TenHuisen KS, Martin RI, Klimkiewicz M, Brown PW. Formation and properties of a synthetic bone composite: hydroxyapatite-collagen. J Biomed Mater Res, v.29, p.803$810,1995$.

Urist MR. Bone: formation by autoinduction. Science, v.150, p.893-899, 1965.

Van Heest A, Swiontkowski M. Bone-graft substitutes. Lancet; v.353 (suppl I), p.28-29, 1999.

Wight TN, Kinsella MG, Qwarnstrom EE. The role of proteoglycans in cell adhesion, 
migration and proliferation. Curr Opin Cell Biol v.4, p.793-801, 1992. 


\section{Figuras e TABElas}


Tabela 1: Tamanho e variação do diâmetro dos poros das matrizes de colágeno aniônico.

\begin{tabular}{cccc}
\hline Matriz & Tamanho do & Valor mínimo & Valor Máximo \\
poro & & & \\
\hline BP24 & $42.54 \pm 23.03$ & 11.34 & 105.5 \\
BP36 & $15.39 \pm 8.59$ & 4.45 & 43.68 \\
BP48 & $52.24 \pm 24.99$ & 14.06 & 134.3 \\
\hline
\end{tabular}

Valores expressos em $\mu \mathrm{m}$. Tamanho do poro: média \pm desvio padrão. 
Tabela 2: Aumento do número de grupos carboxílicos $\left(\mathrm{COO}^{-}\right)^{*}$ de acordo com o tempo de hidrólise e, estabilidade térmica (Ts) das matrizes de colágeno aniônico em comparação com o colágeno nativo (Tempo 0).

\begin{tabular}{|c|c|c|c|c|}
\hline \multirow{2}{*}{$\begin{array}{l}\text { Tempo de } \\
\text { tratamento }\end{array}$} & \multirow{2}{*}{$\begin{array}{l}\text { Aumento } \\
\text { no conteúdo } \\
\mathrm{COO}^{-}\end{array}$} & \multicolumn{3}{|c|}{ Ts } \\
\hline & & pH 3,0 & pH 4,6 & pH 7,4 \\
\hline $\mathbf{0}$ & $235 \pm 8$ & $53,5 \pm 0.63$ & $57,8 \pm 0.95$ & $62,5 \pm 0.14$ \\
\hline 12 & $254 \pm 6$ & $47,2 \pm 1.15$ & $53,2 \pm 0.14$ & $53,3 \pm 0.52$ \\
\hline 24 & $271 \pm 4$ & $46,8 \pm 0.14$ & $53,0 \pm 0.66$ & $52,8 \pm 0.14$ \\
\hline 36 & $287 \pm 4$ & $43,0 \pm 0.80$ & $52,3 \pm 0.14$ & $48,0 \pm 0.38$ \\
\hline 48 & $309 \pm 9$ & $40,3 \pm 0.14$ & $51,5 \pm 0.43$ & $46,3 \pm 0.38$ \\
\hline 72 & $336 \pm 9$ & $40,0 \pm 0.14$ & $49,0 \pm 0.38$ & $44,0 \pm 0.29$ \\
\hline 96 & $364 \pm 7$ & $39,5 \pm 0.29$ & $48,3 \pm 0.14$ & $42,8 \pm 0.25$ \\
\hline
\end{tabular}

* conteúdo de $\mathrm{COO}^{-}$calculado para o colágeno nativo e a matriz com hidrólise de todos os grupos carboxyamidas são respectivamente 231 e 361 . 

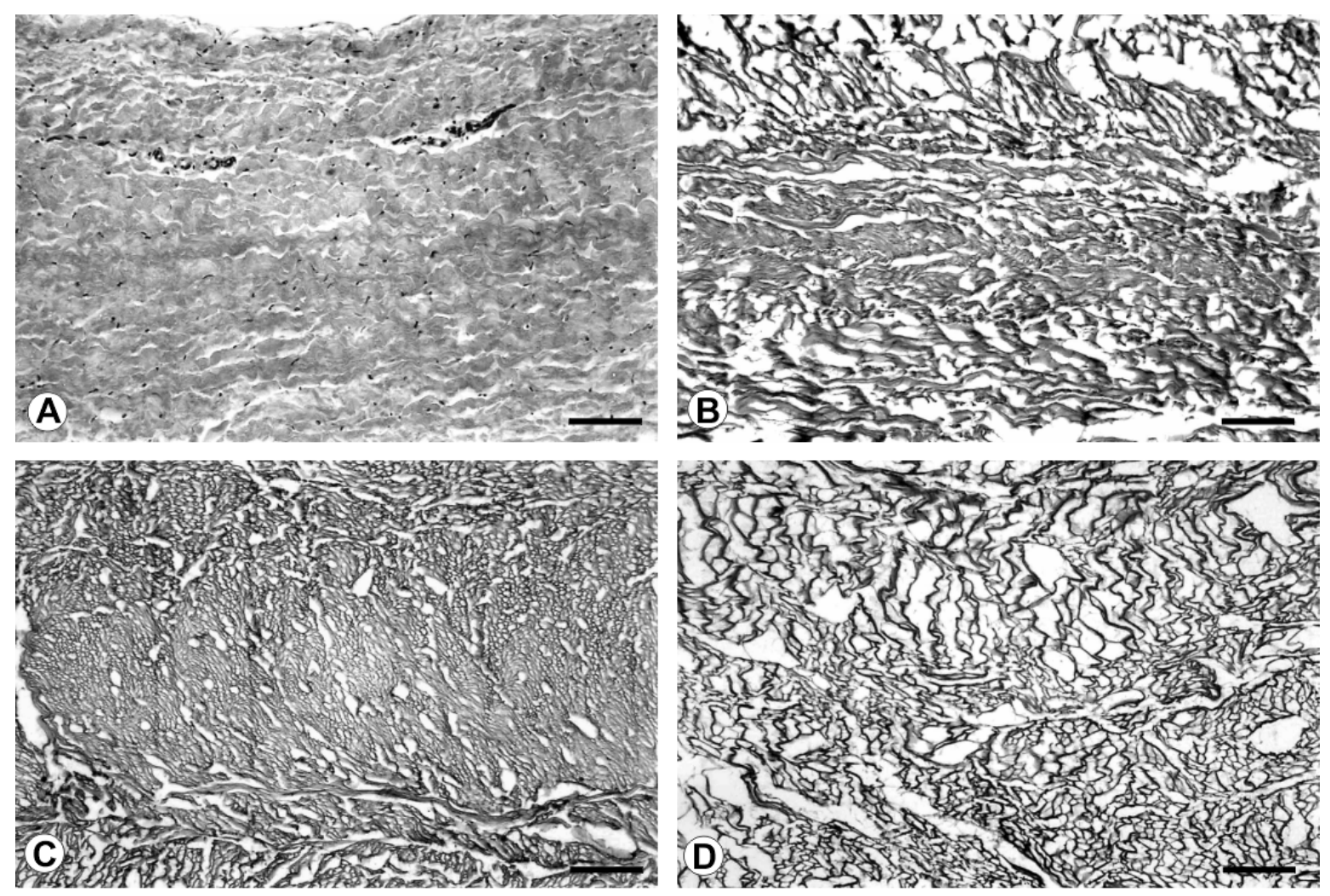

Figura 1: Aspecto microscópico do pericárdio bovino (A) e matrizes BP24 (B), BP36 (C), e BP48 (D). 0 processo de hidrólise removeu as células das matrizes e criou poros de vários diâmetros. Pentacrômico de Movat. Barra $=120 \mu \mathrm{m}$. 

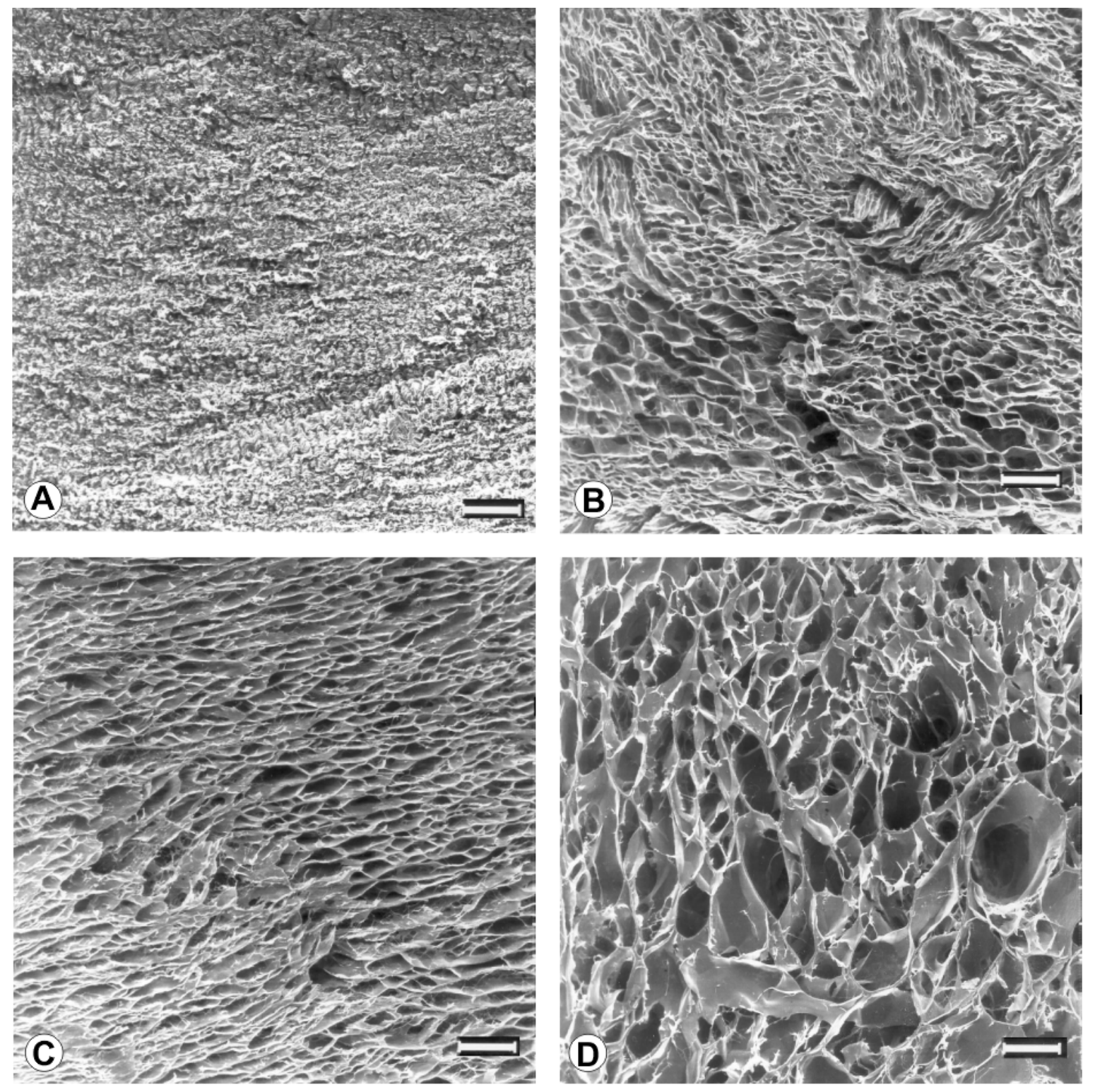

Figura 2: Microscopia eletrônica de varredura do pericárdio bovino (A) e matrizes BP24 (B), BP36 (C), e BP48 (D). Aspecto de esponja das matrizes comparado com aspecto compacto e fibrilar do pericárdio bovino. Barra $=100 \mu \mathrm{m}$. 


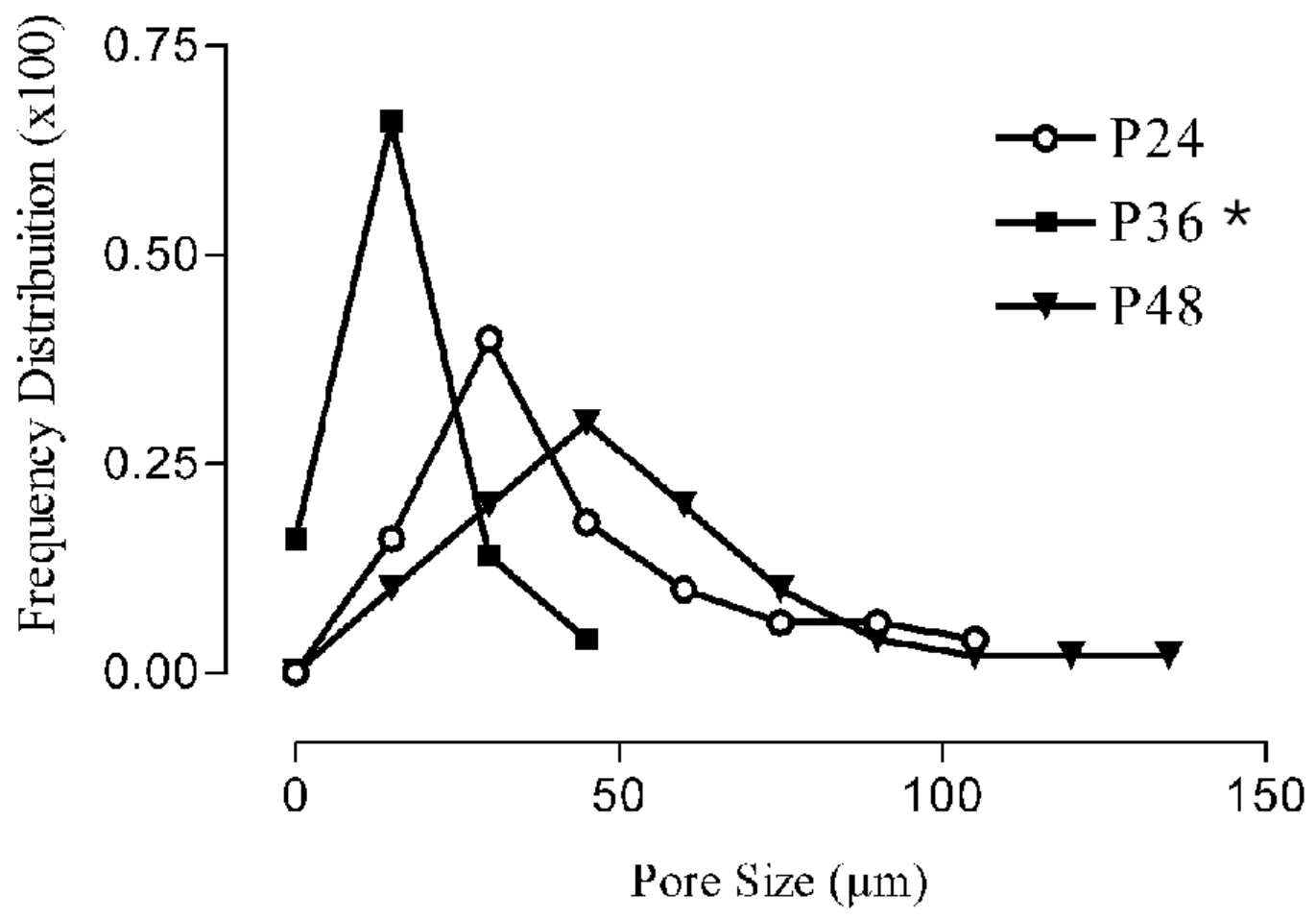

Figura 3: Freqüência de distribuição do diâmetro dos poros nas matrizes colágeno aniônico ${ }^{*} \mathrm{P}<0.05$ (Teste de Bonferroni). 

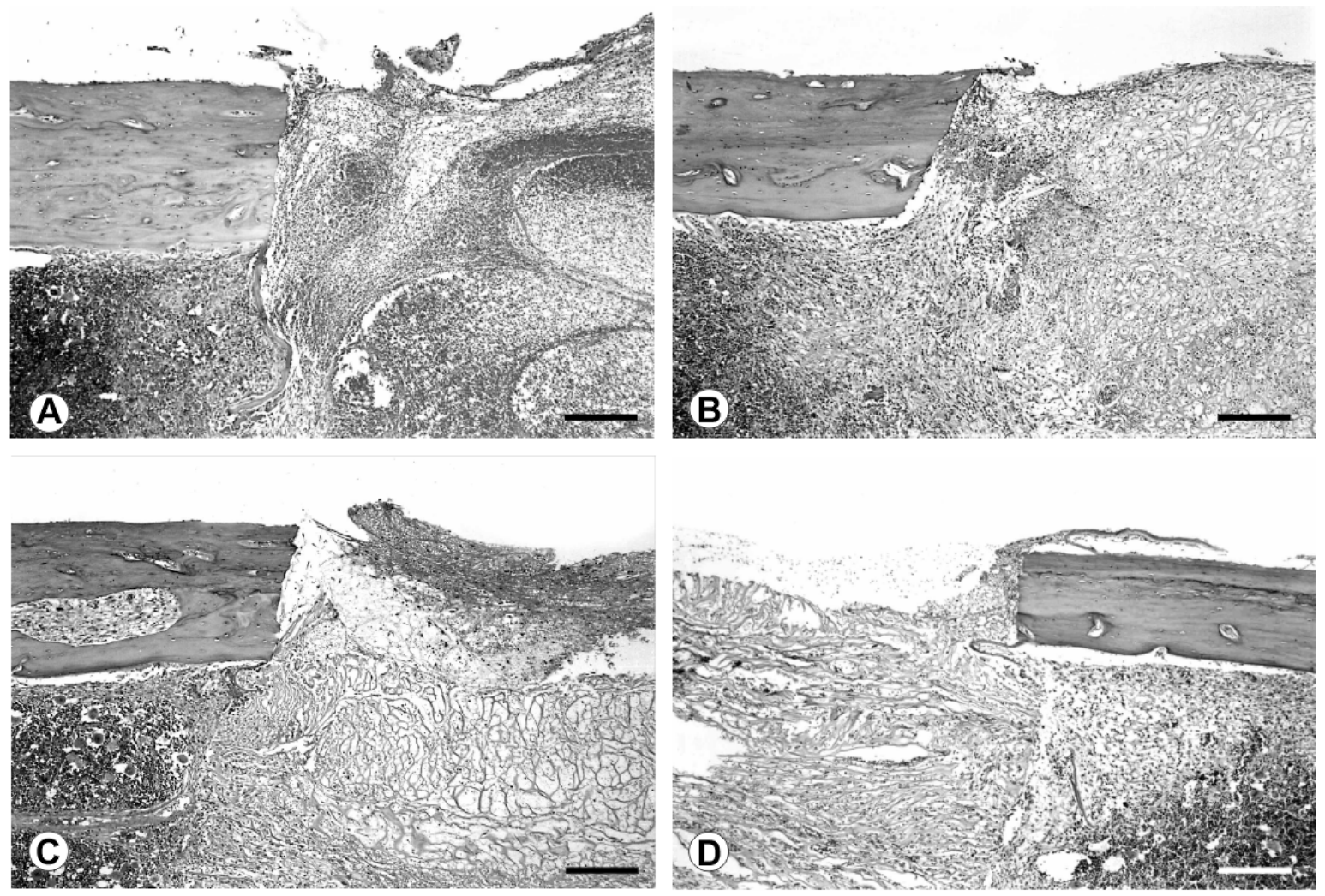

Figura 4: Aspecto microscópico da cavidade vazia (A) e cavidades preenchidas com BP24 (B), BP36 (C), e BP48 (D) três dias após a cirrurgia. A cavidade vazia estava preenchida por um coágulo e as matrizes estavam povoadas por hemácias e algumas células inflamatórias. Hematoxilina e eosina. Barra $=200 \mu \mathrm{m}$. 

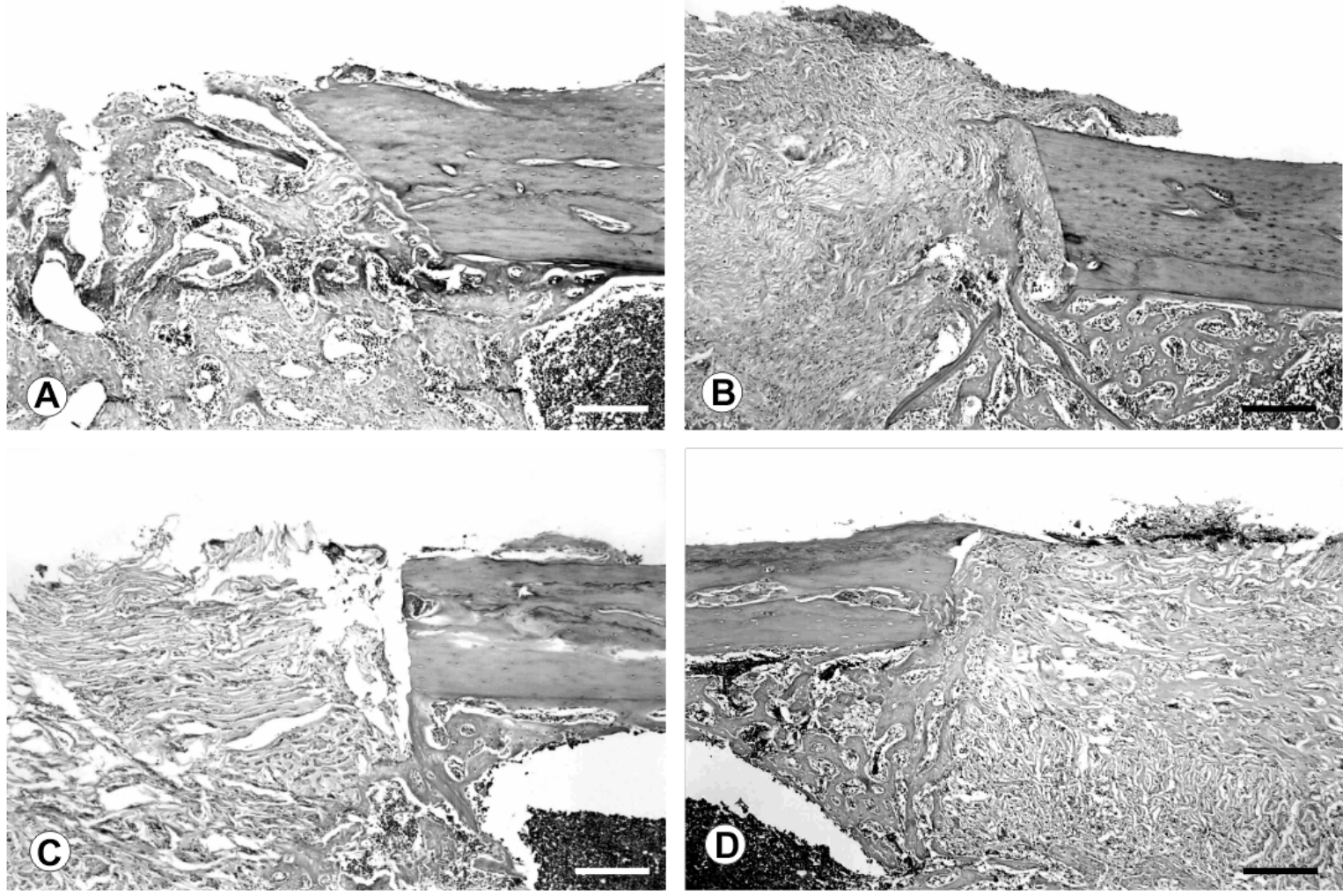

Figura 5: Aspecto microscópico da cavidade vazia (A) e cavidades preenchidas com BP24 (B), BP36 (C), e BP48 (D) sete dias após a cirurgia. A cavidade vazia estava preenchida por osso imaturo e as matrizes povoadas por células inflamatórias e mesenquimais não identificadas. Hematoxilina e eosina. Barra=200 $\mu$ m. 

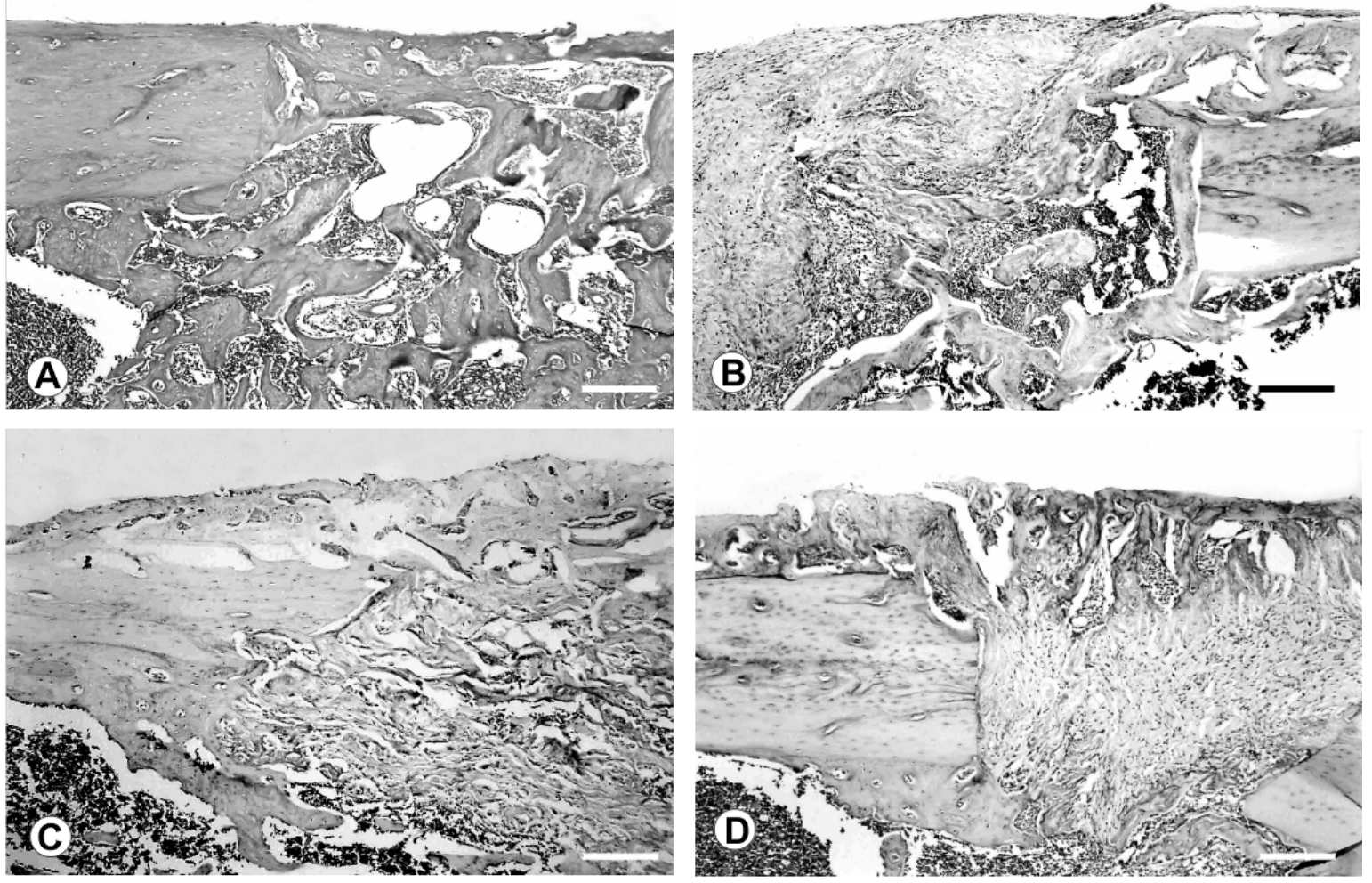

Figura 6: Aspecto microscópico da cavidade vazia (A) e cavidades preenchidas com BP24 (B), BP36 (C), e BP48 (D) $15 \mathrm{~s}$ dias após a cirurgia. 0 osso neoformado na cavidade vazia estava remodelando em osso cortical. Osteogênese

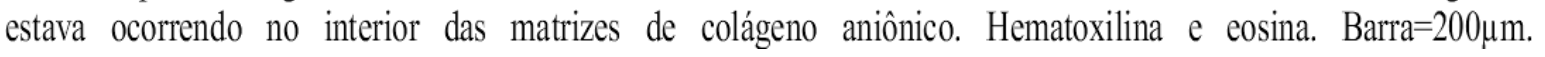



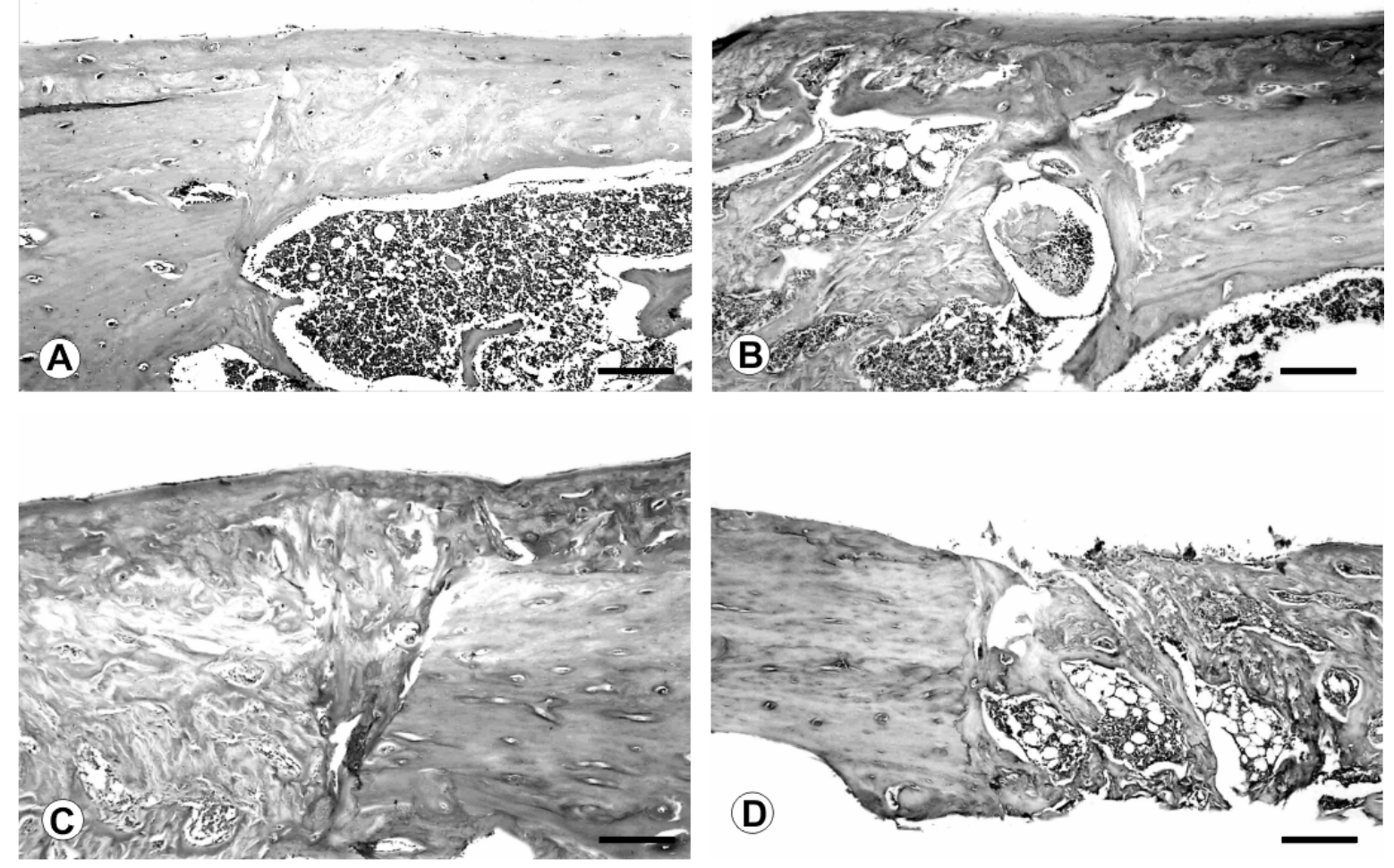

Figura 7: Aspecto microscópico da cavidade vazia (A) e cavidades preenchidas com BP24 (B), BP36 (C), e BP48 (D) 30 dias após a cirurgia. A cavidade vazia estava preenchida por tecido cortical maduro. As cavidades com as matrizes estavam preenhidas por osso trabeculado e medula óssea. Hematoxilina e eosina. Barra $=200 \mu \mathrm{m}$. 

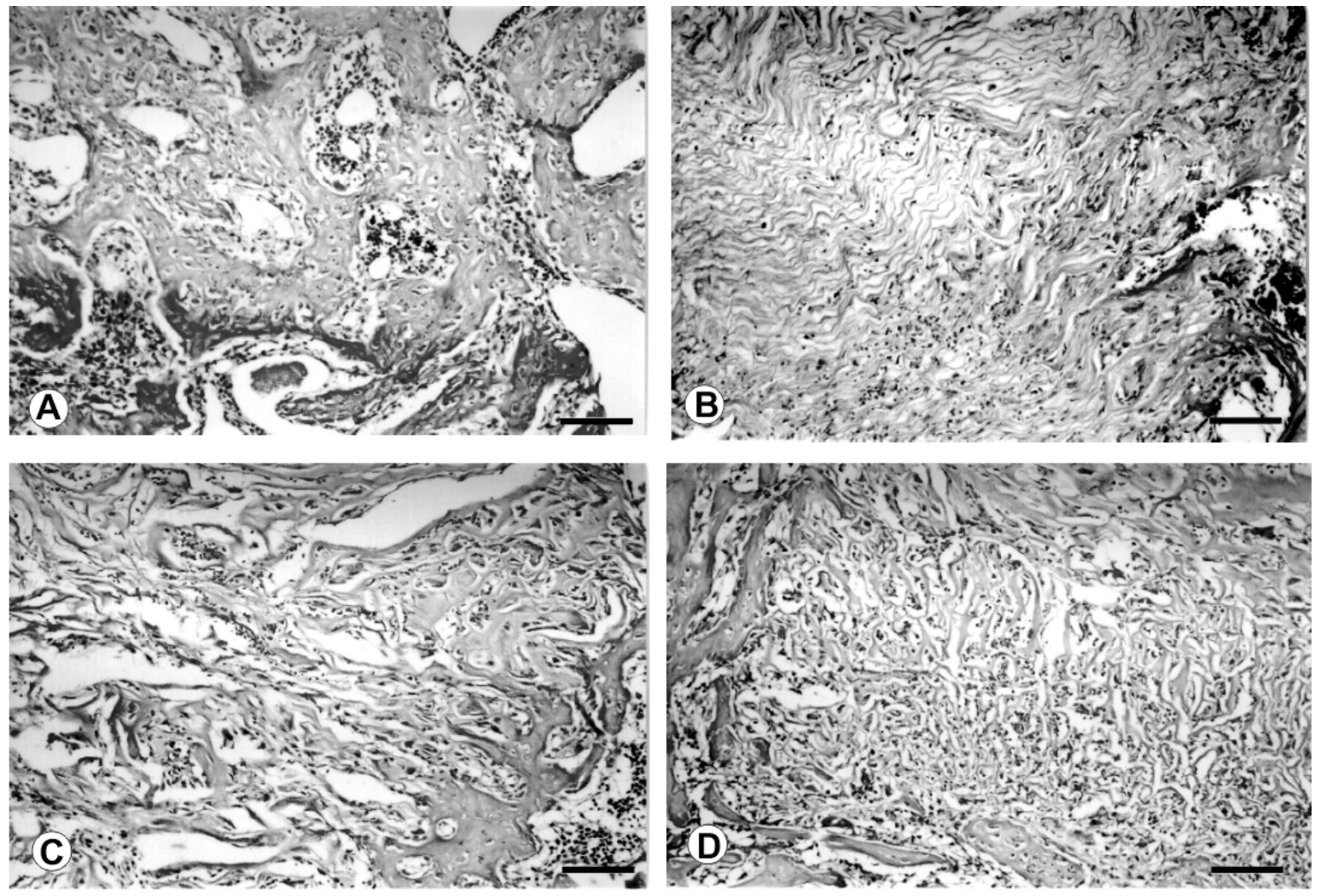

Figura 8: Detalhe da área vista na figura 5. A cavidade vazia (A) estava preenchida por osso imaturo e as matrizes BP24 (B), BP36 (C), e BP48 (D) povoadas por células inflamatórias e mesenquimais não identificadas. Hematoxilina e eosina. Barra=100um. 